Res Publica. Revista de Historia de las Ideas Políticas

ISSN: $1576-4184$

http://dx.doi.org/10.5209/RPUB.62439

\title{
Ortega frente a un pueblo joven
}

\author{
Rodolfo Gutiérrez Simón*
}

Recibido: 4 de junio de 2018 / Aceptado: 4 de septiembre de 2018

Resumen. El presente trabajo pretende mostrar, de manera amplia, cómo se integra la visión orteguiana de América en la filosofía general del autor. Para ello, se abordará la cuestión tanto desde el liberalismo y sus consecuencias como desde el perspectivismo. Será esencial aclarar en qué sentido la concepción orteguiana de la "juventud" puede entenderse de modo positivo y negativo a la hora de caracterizar al pueblo americano, mostrando que supone a la vez un límite y una posibilidad para el continente.

Palabras clave: Ortega y Gasset; América; juventud; liberalismo; perspectivismo.

\section{[en] Ortega Facing a Young People}

\begin{abstract}
This paper analyses Ortega y Gasset's, from a general point of view the way in which Ortega y Gasset's conception of America takes part in his philosophy. In order to do so, firstly, Ortega y Gasset's Liberalism, Perspectivism and its consequences will be revised. Finally, Ortega y Gasset's concept of "Youth" will be undertaken, specifically considering its positive and negative meanings that are used by the author to characterize American people. That characterization is both a limit and a possibility for the American continent.
\end{abstract}

Keywords: Ortega y Gasset; America; Youth; Liberalism; Perspectivism.

Sumario: 1. Introducción. 2. Ortega y América: más allá del Desastre. 3. Vitalidad y juventud: una relación ambivalente. 4. Vitalidad, liberalismo, Estado. 5. Los pueblos jóvenes y el primitivismo. 6. Juventud y futuro de América.

Cómo citar: Gutiérrez Simón, R. (2018). Ortega frente a un pueblo joven, en Res publica 21.3, 517-527.

\section{Introducción}

Hablar de la filosofía de Ortega y Gasset respecto a lo que hoy llamamos América Latina es una tarea que puede llevarse a cabo de formas diversas. Por ejemplo, podríamos estudiar los diversos viajes que realizó hacia aquella región el pensador español, y tratar de destilar las distintas recepciones que en cada país tuvo su obra. Asimismo, podría adoptarse otro enfoque basado en la relación personal de Ortega con distintas personalidades latinoamericanas o que desarrollaron allí su carrera (algo que hoy en día está tratando de ilustrar la Fundación José Ortega y Gasset mediante

\footnotetext{
* Universidad Complutense de Madrid beatrizdavilo@hotmail.com
} 
la publicación de los epistolarios del pensador madrileño con aquellas personalidades, por ejemplo Coriolano Alberini ${ }^{1}$, Alfonso Reyes ${ }^{2}$ o Máximo Etchecopar ${ }^{3}$ ). En tercer lugar, podríamos limitarnos a una enumeración estructurada de las opiniones vertidas por nuestro autor sobre el continente, al que tan inclinado se sentía ya antes de la I Guerra Mundial ${ }^{4}$, tal y como se aprecia en esta afirmación de 1911:

América, muy especialmente Centro y Sud-América, es para nuestra vieja y melancólica sensibilidad metropolitana un enérgico canto de vida y esperanza [...] "Tú eres mi mejor yo" piensa Europa de América, cuando se reconcentra en sí misma allá en las meditaciones de alguno de sus filósofos o historiadores ${ }^{5}$.

En esta ocasión, yo no haré ninguna de esas cosas: lo que voy a intentar es, de manera muy general, incardinar la concepción orteguiana de América en el conjunto de su filosofía, para lo cual me centraré en dos cuestiones íntimamente relacionadas. En primer lugar, voy a integrar la visión que el filósofo madrileño tiene de América (Hispana, aunque no sólo ${ }^{6}$ ) en tanto que pueblo joven, de modo que quede tan claro como sea posible el significado y las implicaciones del concepto "joven"; en segundo lugar, trataré de mostrar -también de manera rápida- que esta filosofía ofrece una posible visión laudatoria y reivindicadora de un valor propio de aquella porción de tierra única (destacando, claro, la importancia de un concepto muy orteguiano: "perspectiva").

\section{Ortega y América: más allá del Desastre}

Los detalles de la vida de Ortega no pueden ser ahora foco de nuestra atención. Baste decir que nació en Madrid en 1883 y murió en la misma ciudad en 1955. Esto es tanto como decir que en 1898, año del Desastre (tal y como se conoció desde estas latitudes la pérdida de las últimas colonias: Cuba, Puerto Rico y Filipinas) tenía el joven Ortega 15 años. Este acontecimiento late de fondo en buena medida en los textos de juventud del filósofo, aparecidos en diversos periódicos. El tono, en cierto modo, difiere del que asociamos a la generación del 98 (ejemplo reciente y magnífico de ello es el trabajo sobre Ganivet que Rafael Herrera incluye en su Adiós América,

$1 \quad$ R. E. Aras (ed. lit.), “José Ortega y Gasset-Coriolano Alberini. Epistolario (1916-1948)”, en Revista de Estudios Orteguianos, n 30, 2015, pp. 39-78.

2 S. Pineda Buitrago (ed. lit.), "Órbitas en pugna. José Ortega y Gasset-Alfonso Reyes. Epistolario (1915-1955)", en Revista de Estudios Orteguianos, n n $^{\circ} 32,2016$, pp. 55-85 (primera parte) y n ${ }^{\circ} 33,2016$, pp. $27-88$ (segunda parte).

3 R. E. Aras (ed. lit.), "José Ortega y Gasset-Máximo Etchecopar. Epistolario (1942-1952)”, en Revista de Estudios Orteguianos, n 34, 2017, pp. 35-77.

4 J. Ortega y Gasset, "Palabras a los suscriptores", en El Espectador II, OC II, 265. Cito las obras de Ortega y Gasset siguiendo la siguiente edición: José Ortega y Gasset, Obras completas, Madrid, Taurus/Fundación José Ortega y Gasset, 2004-2010, 10 vols. Indico el nombre del texto, OC, el tomo en romanos y la página en arábigos

J. Ortega y Gasset, "Problemas culturales", OC I, 470.

6 Señala muy acertadamente E. Rivera que, mientras que al analizar la influencia de Ortega en América hay que destacar sobre todo el ámbito iberoamericano, al tratar de abordar la interpretación orteguiana del hecho americano hay que considerar tanto la América del Norte como la del Sur, sin negar la preeminencia de la primera. Cf. E. Rivera, "América en la filosofía de la historia de Ortega y Gasset", en Cuadernos Salmantinos de Filosofía, Número 10, 1983, p. 107. 
Adiós $\left.{ }^{7}\right)$. Permítame el lector una cita un tanto extensa del año 1903, en la que Ortega comienza citando a Grandmontagne y, a continuación, ofrece su propia opinión:

\begin{abstract}
¿Saben ustedes lo que hay en España? "El fraude en el sufragio, la mentira política y social, el caciquismo agresivo, la corrupción de la justicia, su lentitud mientras duran los bienes del pleito, la concusión, el parasitismo burocrático, el nepotismo, el crónico y flúido [sic] palabreo parlamentario, saturado de ese ingenio inferior que es el talento manqué, frustrado, el desorden administrativo, la incapacidad gubernativa, la pereza, la blandura de raspa, raíz idiosincrásica de los pechos fidalgos: la fe en el azar, el culto de la buena suerte, la esperanza en una lotería general que ha de dar el premio de la riqueza, el premio del cielo, el premio de la salud y hasta el premio de la inspiración en arte".

Todas estas cosas hay en España y unas cuantas más y peores. El señor Grandmontagne arriba de allende los mares para decirnos esto a nosotros que lo tenemos sabido, a nosotros, a quienes nos duele la lengua de repetirlo y los oídos de escucharlo.
\end{abstract}

Si traigo a colación este texto es para evidenciar que las reflexiones de Ortega en torno a 1898 van a tender no tanto a hablar de lo que se ha perdido (las colonias), como de lo que ha quedado: una España caduca y moralmente pobre (en el homenaje que la revista Sur de Buenos Aires realizó al autor por su muerte, señala Segundo Serrano Poncela que "la existencia de una España amarga es la primera lección que recibió el joven Ortega al entrar en contacto con las generaciones maduras"9) que condensa todos sus males en torno a una palabra. Esa palabra, que es a la que quería llegar, va a ser el principal motivo de guerra de Ortega respecto al pasado -y, en buena medida, así será hasta los años treinta, en que sus nocivos efectos parezcan desaparecer-: la palabra Restauración. Aunque ahora me es forzoso soslayar el asunto, conviene señalar que la crítica al periodo restauracionista va a ser lo que dé forma en buena medida al liberalismo orteguiano de principios de siglo; un liberalismo que se ha solido caracterizar como "socialista" 10 .

De esta manera, podemos ver que la reflexión orteguiana respecto a América no va a estar definitivamente marcada por el hecho de la pérdida de poder español allí, pues el Desastre será entendido por él como una manifestación de un problema previo con previsibles consecuencias futuras -si atendemos a los más duros pasajes de España invertebrada, podría proseguir en un proceso de particularización de las regiones españolas ${ }^{11}$ - Entiéndase adecuadamente lo que quiero decir: la pérdida de territorios (y las razones de la misma), al igual que el futuro del pueblo americano a partir de dicha pérdida, serán aspectos de suma importancia en la concepción orteguiana del particular, pero su reflexión sobre América no gira en torno a ello.

\footnotetext{
R. Herrera Guillén, Adiós América, adiós. Antecedentes hispánicos de un mundo poscolonial (1687-1897), Madrid, Tecnos, 2017, pp. 247-282.

J. Ortega y Gasset, "Moralejas", OC I, 13.

S. Serrano Poncela, “Ortega en el Finisterrae”, en Sur, Número 241, Julio y Agosto de 1956, p. 37.

Cf. J. Ortega y Gasset, "La reforma liberal”, OC I, pp. 143-145.

11 No puede dejar de señalarse algo que tiende a olvidarse: el particularismo, entendido en sentido orteguiano, no es sólo un problema geopolítico, sino también social (existe un particularismo de clase); y, naturalmente, en modo alguno es un mal que achaque el autor al elemento particularizado: en este sentido se entiende su idea de que "Castilla ha hecho a España, y Castilla la ha deshecho" (J. Ortega y Gasset, España invertebrada, OC III, 455).
} 
A la luz de esta advertencia previa, podemos comenzar a pensar con Ortega en el papel de América Latina en su filosofía. Para ello -lo advierto ya- voy a tratar de dar la visión de conjunto que tiene él sobre la vida americana; consignado ha de quedar, sin embargo, que para él no todos los países serán igualmente considerados: destaca particularmente Argentina, que visitó tres veces y que le produjo gozos y sombras en el ánimo ${ }^{12}$, convirtiéndose dicho país en "el primer y principal receptor de sus influencias en ultramar, tanto directamente, gracias a sus propias obras, como indirectamente"13; son conocidas sus amistades y sus polémicas con toda una pléyade de intelectuales (hombres y mujeres) de allende los mares, desde los Borges hasta Alfonso Reyes, desde el grupo de Amauta encabezado por Mariátegui hasta Victoria Ocampo. Todo esto, insisto, queda consignado, pero fuera de esta investigación.

\section{Vitalidad y juventud: una relación ambivalente}

La reflexión general en torno a la América del Sur tiene un cierto tono ambivalente (peyorativo y laudatorio) que encaja en el sistema general orteguiano. La idea latente, y muchas veces patente, es la concepción de aquellas tierras como lugares “jóvenes", inmaduros, en los que aún no hay una base firme sobre la que arraigar lo demás. Todo lo más que tienen por sustento es, claro está, lo que el europeo ha llevado hasta allí; en este sentido, no sorprenderá a nadie que Ortega sea un eurocéntrico "euroorgulloso" (Gray señala que Ortega era incapaz de evitar la condescendencia al hablar hacia los americanos $\left.{ }^{14}\right)$, como se puede apreciar en citas tales como la siguiente:

Cada día que pasa afirma Grecia más enérgicamente su posición hors ligne en la historia del mundo. Este privilegio se apoya en títulos perfectamente concretos y definidos: Grecia ha inventado los temas substanciales de la cultura europea, y la cultura europea es el protagonista de la historia, mientras no exista otra superior ${ }^{15}$.

Este es, por lo tanto, el cauce de fondo por el que corre el río de la reflexión toda de Ortega sobre América. A partir de aquí cabría hablar sobre la recepción que hace de Hegel sobre el particular (una recepción que, tal y como se ve por ejemplo en "Hegel y América", incluye una buena parte de crítica en lo tocante a algunas tesis hegelianas sobre el continente americano), etc. ${ }^{16}$.

12 Sobre Ortega y sus relaciones biográfico-intelectuales con Argentina pueden verse: M. M. Campomar, Ortega y Gasset en La nación, Buenos Aires, El Elefante Blanco, 2003; M. M. Campomar, Ortega y Gasset: Luces y sombras del exilio argentino, Madrid, Biblioteca Nueva, 2016. De manera más integrada en su biografía, pueden consultarse sobre sus viajes a Argentina particularmente: J. Zamora Bonilla, Ortega y Gasset, Barcelona, Plaza y Janés, 2002, pp. 160 ss., 266 ss. y 431 ss.; J. Lasaga Medina, José Ortega y Gasset (1883-1955). Vida y filosofia, Madrid, Biblioteca Nueva - Fundación José Ortega y Gasset, 2003, especialmente el capítulo IV.1 (pp. 77-81) sobre el segundo viaje. Por último, más “poética”, la biografía más reciente: J. Gracia, José Ortega y Gasset, Madrid, Taurus-Fundación Juan March, 2014, pp. 227 ss., 407 ss. y 548 ss.

13 R. Gray, José Ortega y Gasset. El imperativo de la modernidad, Madrid, Espasa-Calpe, 1994, p. 134.

$14 \quad$ Ibidem, p. 199.

15 J. Ortega y Gasset, Meditaciones del Quijote, OC I, 774.

16 Sobre la presencia de Hegel en Ortega, me limito a recomendar un artículo reciente: A. Sánchez Cuervo, “Ortega y Hegel. La interpretación de la historia y sus trampas", en Daimon. Revista Internacional de Filosofia, $\mathrm{n}^{\circ}$ 67, 2016, pp. 57-72; y uno más antiguo: J. L. Gómez-Martínez, "Presencia de América en la obra de Ortega y Gasset", en Quinto Centenario, n6, 1983 (Ejemplar dedicado a: Ortega y América), pp.125-160, en particular a partir de la página 134 . 
Ahora bien, mi interés, más que mostrar cuánto de hegeliano es o deja de ser el autor madrileño, consiste en señalar cómo la concepción de América como una tierra joven no desentona respecto al uso que da a la concepción de la "juventud" a lo largo de su obra. Esto, de nuevo, tiene su cara positiva y su cara negativa. Comencemos por la segunda: la juventud es el ámbito de la vida en que destaca, por encima de cualquier otra cosa, lo que Ortega llama vitalidad. Aunque veremos que desde este mismo punto arranca lo "bueno" que América tiene, una breve excursión terminológica nos mostrará que vitalidad encierra algo sumamente oscuro.

En el año 1925, publica Ortega en el marco de El Espectador $V$ un texto de enorme importancia y (a mi humilde manera de ver) un tanto desatendido: "Vitalidad, alma, espíritu"; con él, pretende apuntar el autor hacia una síntesis o integración entre los dos ingredientes humanos clásicamente conflictivos: alma y cuerpo. Vitalidad, alma y espíritu son, dicho de manera rápida, tres instancias o regiones de la personalidad ${ }^{17}$, que no se dan por separado aunque en cada individuo (y en cada momento de una vida) primará una sobre las otras. Como Ortega se explica a sí mismo mucho mejor de lo que yo podría hacerlo, acudiré a una cita en la que la vitalidad queda definida de un modo más o menos claro:

A este alma carnal, a este cimiento y raíz de nuestra persona debemos llamar "vitalidad", porque en ella se funden radicalmente lo somático y lo psíquico, lo corporal y lo espiritual, y no sólo se funden, sino que de ella emanan y de ella se nutren. Cada uno de nosotros es ante todo una fuerza vital: mayor o menor, rebosante o deficiente, sana o enferma. El resto de nuestro carácter dependerá de lo que sea nuestra vitalidad ${ }^{18}$.

Este fenómeno (pues Ortega considera que está describiendo un hecho, no haciendo una hipótesis); este fenómeno, decía, de la vitalidad aparece claramente ligado al cuerpo ("alma carnal" lo ha llamado), y el desarrollo del texto apuntará más claramente a la íntima relación entre vitalidad y juventud: la vitalidad por excelencia viene encarnada por el niño, que es casi todo cuerpo (más concretamente, carne: la carne es el cuerpo que muestra de algún modo que encierra una interioridad; los cuerpos humanos son "carne"19, y también los animales, pero no el vegetal o el mineral). Así, el niño es ante todo una "fuerza vital", y según cuán energética sea, su vida tomará uno u otro perfil.

El "problema" de todo esto, naturalmente, es que el niño es para Ortega (junto con el aventurero temerario) el ser que no tiene "vocación"20; y la "vocación" es el concepto ético fundamental del pensador español ${ }^{21}$. No deja de ser el niño $-\mathrm{y}$

\footnotetext{
Cf. J. Ortega y Gasset, "Vitalidad, alma, espíritu”, OC II, 570.

Ibidem.

19 Esta idea es recurrente en Ortega; véase especialmente J. Ortega y Gasset, El hombre y la gente, OC X, 194 y 214 y ss.

20 El niño no tiene aún vocación por carecer de lo que Ortega denomina "centro"; cf. J. Ortega y Gasset, "Vitalidad, alma, espíritu”, OC II, 582; sobre la carencia de vocación del aventurero, véase J. Ortega y Gasset, "Prólogo a Aventuras del capitán Alonso de Contreras", OC VI, pp. 334-352.

21 Aunque es un concepto disperso aquí y allá en la obra de Ortega, queda especialmente tematizado en J. Ortega y Gasset, "Pidiendo un Goethe desde dentro.-Carta a un alemán", en Goethe desde dentro, OC V, 120-142; y puede complementarse con "Muerte y resurrección", en El Espectador II, OC II, 283-288. Sobre la ética de Ortega han aparecido numerosos libros y artículos desde muy diversas perspectivas, siendo especialmente des-
} 
por analogía todo lo joven, como el continente americano- un puro futuro, cuyo presente no está claro y por lo cual sus posibilidades son infinitas para bien... y para $\mathrm{mal}^{22}$.

Cerrado ese punto, retornemos a nuestro camino con la nueva idea en la mochila: América es una tierra joven, desmesuradamente apegada a la vitalidad, que hasta ahora se nos ha presentado con un tono ciertamente negativo. En el caso concreto del continente americano se encuentra, además, otro hándicap que debe ser mencionado: uno de los rasgos típicos de la juventud - que ya hemos vinculado a la vitalidad-es la prepotencia. Este comentario adquiere sentido si nos aproximamos a un texto de Ortega muy relevante para una investigación como la que estoy llevando a cabo, a saber: "Meditación del pueblo joven". Señala ahí el autor, a propósito de la existencia colonial del hombre americano, lo que sigue:

[...] consiste en el anacronismo entre un repertorio de medios muy perfectos y un repertorio de problemas muy simple. Sin perder ninguna definitiva ventaja ha descendido unos siglos abajo, se ha instalado en una zona vital más fácil. Consecuencia, sentimiento de prepotencia. El mismo hombre se siente en la nueva tierra más capaz que en la antigua. Primer síntoma de juventud: sentir sobra de poderío, en rigor, petulancia ${ }^{23}$.

\section{Vitalidad, liberalismo, Estado}

Ahora bien, en el pensamiento orteguiano la vitalidad es también algo extremadamente positivo. Precisamente, es en la apuesta por la vitalidad donde va a clavar sus raíces el liberalismo que defenderá tanto en su primera etapa anti-maurista (antes me referí a ella) como en un segundo liberalismo (entre 1914 y 1930, aproximadamente)

tacables las siguientes referencias: J. L. López Aranguren, La ética de Ortega, Madrid: Taurus, 1966; J. Lasaga Medina, Figuras de la vida buena, Madrid: Enigma Editores, 2006; o P. Cerezo Galán, José Ortega y Gasset y la razón práctica, Madrid: Biblioteca Nueva, 2011. Sin embargo, pese a su indudable centralidad, considero que el concepto de vocación es, en el mejor de los casos, problemático en la obra de Ortega (y ello por diversos motivos: a mi modo de ver, la ética de Ortega no está construida de un modo plenamente satisfactorio y, además de ello, resulta difícilmente aplicable a la vida efectiva de las personas), algo que no toda la crítica ha notado. He trabajado sobre estos puntos en dos artículos: R. Gutiérrez Simón, "Sobre la interpretación del concepto orteguiano de 'vocación"”, en Revista de Estudios Orteguianos, n 31, 2015, pp. 115-139; y R. Gutiérrez Simón "Los límites del sujeto y la libertad en Ortega y Gasset", en Daimon. Revista Internacional de Filosofia, n ${ }^{\circ}$ 69, 2016, pp. 109-123. Asimismo, mi interpretación sobre la relación entre la ética de Ortega y la corporalidad puede verse en: R. Gutiérrez Simón, "Dimensiones del cuerpo y conocimiento moral en Ortega y Gasset", en Azafea: revista de filosofí, $\mathrm{n}^{\circ}$ 18, 2016, pp. 227-244.

22 Aunque no es esencial para la argumentación que estoy desarrollando, creo que debo complementar lo dicho señalando que el "alma" (recordemos que la tríada está formada por vitalidad, alma y espíritu) sería esa instancia humana en la que gobiernan en cierto modo las pasiones, los afectos, las emociones (en sentido negativo, pero también las altas pasiones, como el amor); el espíritu, por su parte, sería la dimensión de lo racional, de lo esencialmente comunicable, de la claridad instantánea de la ciencia. Si la vitalidad era lo asociable de forma nítida al niño, el alma será la instancia predominante en las mujeres y el espíritu, la que destaque entre los hombres. Llamo "claridad instantánea" al hecho de que podemos tardar en entender que $2+2=4$, pero lo entendemos de golpe (y, por tanto, instantáneamente); lo anímico, esto es, lo relativo a la dimensión del alma, tiene duración ("estoy contento" un rato o una vida entera). Esto lo resume Ortega señalando que "Los fenómenos espirituales o mentales no duran; los anímicos ocupan tiempo" ("Vitalidad, alma, espíritu", OC II, 575).

23 J. Ortega y Gasset, "Meditación del pueblo joven”, OC IX, 272. 
de corte clásico milliano ${ }^{24}$. Para explicarme del modo más rápido posible, voy a centrarme en un ejemplo: el nacimiento de, y el terrible peligro que es, el Estado.

Frente al mito del contrato como fundación del Estado ${ }^{25}$, Ortega va a oponer otro $^{26}$ : el del rapto de las sabinas. Sobre este particular, su texto esencial será "El origen deportivo del Estado" (que se encuentra en El Espectador VII, significativamente el mismo volumen en que aparece "Hegel y América"), y para nuestros intereses podemos resumirlo de un modo sencillo: el origen "deportivo" del Estado es "deportivo" en la medida en que procede de un exceso de vitalidad. Los jóvenes de la tribu pre-estatal acaban en cierto modo reunidos y un temperamento más sagaz que los otros, al percibir por vez primera el asco hacia la mujer de la misma sangre, propone la audacia genial: habiendo mujeres en la cercanía, harán el más difícil todavía y raptarán a las damas de la tribu vecina. Nótese aquí, insisto, que la alusión al deporte ha de vincularse al exceso, al lujo, a imponerse una norma difícil cuando no era necesario. Son, pues, estos jóvenes los que fundan el Estado mitológicamente, y la familia y otras agrupaciones sociales serán precisamente el modo de defenderse de él que tienen las mujeres, los niños y, en definitiva, los no jóvenes reunidos en casinos.

Ocurre, sin embargo, que toda vida acaba enquistándose, esclerotizándose en instituciones "muertas". El Estado, que era fruto de la más explosiva vitalidad, es pasado el tiempo (cultura mediante) una máquina estrictamente mecánica, cuyos resortes funcionan automatizados, de forma radicalmente opuesta a la espontaneidad. Este Estado (lo digo, como todo, muy apresuradamente) está a comienzos del siglo XX a merced de los hombres-masa, que no dudarán en activarlo ante cualquier originalidad creativa, ante todo lo que se salga de la norma, ante cualquier acto puramente vital organizado por una minoría; de ahí que el último capítulo de la primera parte de La rebelión de las masas lleve un título que resulta cautivador: "El mayor peligro, el Estado". Véase cómo de la juventud y espontaneidad más puras pueden derivarse los más grises mecanismos cuando se les despoja de la vida ${ }^{27}$.

24 Sobre las tres etapas en las que típicamente se divide el liberalismo de Ortega, véase: J. M. Díaz Álvarez, "Cuestión de libertad. Ética y filosofía política", en J. Zamora Bonilla (ed.), Guía Comares de Ortega y Gasset, Granada, Comares, 2013, pp. 251-286. Asimismo, puede consultarse el aún más reciente estudio de José Lasaga sobre la evolución del "ideal liberal" en Ortega, aunque a diferencia de Díaz Álvarez, Lasaga encuentra cuatro divisiones en el liberalismo de Ortega: J. Lasaga Medina, "El liberalismo itinerante de Ortega y Gasset”, en J. Lasaga Medina y A. López Vega, Ortega y Marañón ante la crisis del liberalismo, Madrid, Cinca - Fundación José Ortega y Gasset - Gregorio Marañón, 2017, pp. 15-78, especialmente pp. 25 ss.

25 Ortega deplora (en general) la fundación contractual del Estado, así como de toda sociedad articulada en torno a contratos (quebrando la dignidad de las relaciones personales, fundadas en el honor, que articulaban la Edad Media) por cuanto son consecuencia de una Modernidad que atenderá desde una perspectiva crítica. Así, en el texto en el que más claramente se concentra su interpretación del liberalismo, "Notas del vago estío", no duda en hablar del contrato como "la cínica declaración de que desconfiamos del prójimo al tratar con él y le ligamos a nosotros en virtud de un objeto material -el papel del contrato- que queda fuera de las dos personas contratantes, y en su hora podrá -vil materia que es- alzarse contra ellas. ¡Grave confesión de la modernidad! Fía más en la materia, precisamente porque no tiene alma, porque no es persona. Y, en efecto, esta edad ha tendido a elevar la física al rango de teología" (OC II, 459). Decía antes, no obstante, que Ortega reniega de la concepción contractual del Estado "en general", pero no siempre; en este sentido, puede verse cierto acercamiento favorable hacia la idea del contrato en "El genio de la guerra y la guerra alemana", OC II, 328.

26 No por casualidad va a recurrir nuevamente a un mito: aunque las explicaciones científicas (en el sentido usual que damos a este término) resultan ser infinitamente más precisas, son también incompletas, ya que no responden a preguntas últimas; el mito, que es mucho menos riguroso, nos ofrece una totalidad. Cf. "El origen deportivo del Estado", OC II, 706.

27 No uso aquí la expresión vitalidad porque daría lugar a confusión: no se trata de la vitalidad de la que he venido hablando hasta aquí, sino de un sentido mucho más laxo del término tal que el aparecido en Vieja y nueva política o, de manera tematizada, en El tema de nuestro tiempo. 
Pero volvamos ahora al sugerente título que Ortega dio a una conferencia ya mencionada aquí: "Meditación del pueblo joven", cuyo título reconoce el autor que es "un poco añagaza y superchería bien intencionada" 28 . Encontramos en dicho texto un tópico de la filosofía orteguiana, a saber: que todo lo humano tiene una edad (desde la infancia a la muerte). En este sentido, apunta:

Los caracteres de la juventud [que es lo que nos viene ocupando en esta intervención] aparecen, como casi todas las cosas, más claros y obvios en los cuerpos vivientes. Y, sin embargo, es incuestionable que esto que llamamos las almas también son siempre de una u otra edad $^{29}$.

Creo que, a la luz de afirmaciones como la indicada, la alusión por mi parte a la vitalidad, al alma corporal, queda, al menos parcialmente, justificada (dado que era un objetivo de este texto presentar la interpretación orteguiana de América como coherente con otros planos de su filosofía).

\section{Los pueblos jóvenes y el primitivismo}

Llegados a este punto, conviene realizar una precisión a la que apunté indirectamente antes: Ortega va a analizar en "Meditación del pueblo joven" -dicho sea de paso, de manera muy somera- el sentir de los "pueblos jóvenes"; pero... ¿a qué va a considerar tales? Sólo a una clase de pueblos jóvenes de entre los muchos posibles: los de nacimiento colonial ${ }^{30}$. En este sentido, atenderá a una categoría esencial, el "hecho colonial", que no es meramente la colonización sino, al contrario, el proceso todo que la continúa ${ }^{31}$ y que en América Latina (particularmente en Argentina, donde la conferencia tiene lugar) estaría finalizando para cuando Ortega escribe este texto (1939). Este "estar dejando de ser" de la antigua colonia manifiesta dos características de la vida colonial que sólo enunciaré: en primer lugar, que la vida colonial es sólo etapa, un momento hacia otro (y añado, pues Ortega no lo dice, que esto es también lo propio de la juventud); y en segundo lugar, que es vida no autóctona: es un hombre extranjero el que se asienta en la región; hombre de cultura vieja que llega cargado de técnica a un pedazo de universo poco problemático: aquí es donde alcanza su plena significación la cita que referí con anterioridad sobre la particular petulancia del joven, un joven que empieza siendo un rejuvenecido poblador de una cultura senil (contrástese esta idea con el análisis que hace Ortega a partir de las tesis de Toynbee sobre la génesis de la civilización a partir de la sociedad primitiva en torno al concepto de challenge ${ }^{32}$ ).

Acontece entonces un fenómeno nuevamente ambivalente: ese hombre que lleva en la mochila toda la antigüedad de la cultura (europea), tras algún tiempo en un territorio tan favorable, desciende a lo meramente elemental: los refinamientos

\footnotetext{
J. Ortega y Gasset, “Meditación del pueblo joven”, OC IX, 268.

Ibidem, OC IX, 269.

Cf. Ibidem.

31 Que Ortega distingue nítidamente la colonización de la Conquista de América (preludio ésta de aquélla) se aprecia en España invertebrada, OC III, 504.

32 J. Ortega y Gasset, Sobre una nueva interpretación de la historia universal. Exposición y examen de la obra de Arnold Toynbee: A Study of History, especialmente la lección X, OC IX, 1351-1368.
} 
íntimos se abandonan ante la nuda robustez que el contorno exige del sujeto. Se produce, en suma, una vuelta al primitivismo del ser del individuo sin perder su modernidad material y aun social. De ese desequilibrio depende el encanto que dice Ortega encontrar en el individuo colonial ${ }^{33}$. Tal cosa ha de resultar, por fuerza, chocante en un primer momento. Primitivismo es una palabra de gran presencia en momentos cruciales de la obra de Ortega (llegando éste a considerar que la "vida primitiva" es "uno de los temas más apasionantes que existen" $\left.{ }^{34}\right)$. Piénsese, por ejemplo, en dos capítulos tan centrales de La rebelión de las masas como son el IX y el X de la Primera parte, respectivamente llamados "Primitivismo y técnica" y "Primitivismo e historia" ${ }^{35}$ : ahí el primitivismo es una de las características esenciales del hombre-masa. ¿Es, por ventura, hombre-masa y vida vulgar ${ }^{36}$ el americano de comienzos del siglo XX?

Naturalmente, sólo desde una visión miope puede caerse en ese equívoco. El hombre-masa típicamente primitivo que estudia Ortega en La rebelión de las masas es un individuo europeo, nacido en una cultura milenaria. En dicho contexto, el primitivismo adquiere su plena carga peyorativa: ese europeo que empieza a predominar es primitivo "relativamente a la compleja civilización en que ha nacido" ${ }^{37}$. Sin embargo, en un pueblo joven el primitivismo es lo temporalmente adecuado al tiempo vital y, por ende, un síntoma inequívoco de salud ${ }^{38}$; pensemos (el ejemplo es mío) en lo extraordinariamente insoportable que resulta un niño que, de manera impropia para su edad, adopta las costumbres y el carácter de un viejo; tanto, como el adulto que, despreciando su edad y queriendo ser "joven", es calificado a su pesar como "pueril". Así, señala Ortega respecto a este pueblo mozalbete:

33 J. Ortega y Gasset, "Meditación del pueblo joven”, OC IX, 272-274. Llama la atención esta idea si se pone en contraste con otra aparecida en La rebelión de las masas: "la vida humana ha surgido y ha progresado sólo cuando los medios con que contaba estaban equilibrados por los problemas que sentía" (OC IV, 436). Habría que dirimir hasta qué punto el hecho de que, como se va a señalar a continuación, la crítica de $L a$ rebelión de las masas esté orientada al europeo del siglo XX anularía la aparente contradicción entre la cita indicada aquí y el encanto que Ortega siente ante el desequilibrio del pueblo joven a que me refiero en el cuerpo del texto.

34 J. Ortega y Gasset, sobre una nueva interpretación de la historia universal. Exposición y examen de la obra de Arnold Toynbee: A Study of History, OC IX, 1352. Debo esta referencia expresa a uno de los evaluadores o evaluadoras de este artículo, a quien quedo enormemente agradecido.

35 J. Ortega y Gasset, La rebelión de las masas, OC IV, 421-433.

36 Nótese la alusión aquí a otro capítulo de La rebelión de las masas, "Vida noble y vida vulgar, o esfuerzo e inercia" (OC IV, 410-414).

37 J. Ortega y Gasset, La rebelión de las masas, OC IV, 427. En cursiva en el original.

38 Aunque Ortega no lleva a cabo el comentario indicado, parece perfectamente plausible sostenerlo. Así, si acudimos a un texto tan decisivo para comprender su liberalismo como "Notas del vago estío" (y, concretamente, al apartado VI, "Ideas de los castillos: espíritu guerrero"), encontramos afirmaciones como la siguiente: "El vocablo «barbarie», en su uso más frecuente, se ha vaciado de significación propia y conserva sólo un sentido peyorativo de descalificación. Lo mismo pasa con la palabra «salvaje». Se olvida que una y otra significan dos tipos de espiritualidad que constituyen dos estadios ineludibles del desarrollo histórico, como en la vida individual lo son la niñez y juventud. Y lo mismo que sería un error considerar únicamente normal y estimable la etapa de madurez - como si infancia y mocedad fuesen dos enfermedades-, es una equivocación desdeñar la barbarie y el salvajismo. Fuera más discreto prestar suma atención a esta gran perogrullada: la civilización es hija de la barbarie y nieta del salvajismo. Comprendo que las épocas privadas de sentido histórico, incapaces de ver en toda realidad su evolución y su génesis, se quedasen sólo con la forma civilizada de la vida y no supiesen descubrir en la forma bárbara más que valores negativos [...] la cultura no nace de la cultura, sino de potencias y virtudes preculturales que dan en ella su fruto. Toda cultura tiene su raíz en la barbarie, y toda renovación de la cultura se engendra en ese fondo de barbarie, y cuando éste se agota, la cultura se seca, se anquilosa y muere. Es, pues, falso querer lo uno sin lo otro" (OC II, 544-545). 
El encanto y la magia juveniles de este pueblo está más allá del plano burgués en que las cosas son agradables o desagradables. Es, repito, que la vida aquí tiene otra edad que en Europa, y es, quieran ustedes o no, hagan lo que hagan contra ello, una vida adolescente. Podrán los individuos ser o dárselas de revejidos y complicados y herméticos, pero ella, la vida, la vida de ellos y por tanto el aura ambiente, es moza, elástica, impetuosa, ardiente ${ }^{39}$.

Traigo a colación esta cita porque, de nuevo, encierra ideas que la lectura pasajera no detecta: es enormemente significativo que la vida americana aparezca caracterizada como elástica, pues la elasticidad (social) ${ }^{40}$ es precisamente una de las características más distintivas de una sociedad sana, tal y como se refleja en España invertebrada; y es también la elasticidad, qué duda cabe, uno de los rasgos propios del cuerpo juvenil.

\section{Juventud y futuro de América}

La juventud americana (diferente en sus caracteres concretos en el norte y en el sur), es entonces la condición necesaria para caracterizar a América como la tierra del futuro $^{41}$. Lo que ella sea o deje de ser está por ver, y el tiempo será el que juzgue. Curiosa frase hecha: el tiempo será el que juzgue; pero el que juzgue... ¿qué? Algo verdaderamente enigmático: si, siguiendo los dictados del poeta Píndaro, el continente ha llegado a ser el que es. Este "Llega a ser el que eres" es la máxima de la ética orteguiana; una ética que, pensada para el plano individual, tiene traducción colectiva: hay un ideal perfil de lo que el sujeto (individual o colectivo) debería ser, perfil marcado por las circunstancias; la libertad radica, precisamente, en la aceptación o no de dicho perfil ideal, al que Ortega da el nombre de vocación y a la que me he referido más arriba ${ }^{42}$.

Es relevante lo que acabo de comentar porque la vocación (insisto, colectiva en este caso) es sólo una para cada sujeto; pero también es cierto que la vocación de cada cual es única e insustituible. En este sentido, la tarea que la circunstancia requiera de América y del americano sólo por América y por el americano podrá ser hecha, y si no, no será (graciosamente señala Ortega en España invertebrada que

39 J. Ortega y Gasset, Meditación del pueblo joven, OC IX, 274.

40 El concepto de "elasticidad social" aparece en España invertebrada, OC III, 460. Asimismo, en un texto tan relevante como "El poder social", reaparece esta idea de la elasticidad social, con la finalidad de mostrar lo poco elástica -y por ende, poco sana- que es la sociedad española respecto a la francesa; cf. OC II, 103.

${ }^{41}$ No puedo dejar de señalar que hay otras causas que llevan a la misma consecuencia: la consideración de América como lugar del futuro. En este sentido, conviene destacar, por ejemplo, la obra de Edmundo O'Gorman, historiador mexicano indudablemente influido por la filosofía orteguiana. Así, señala: “....al inventar a América y más concretamente, al concebir la existencia de una "cuarta parte" del mundo, fue como el hombre de la Cultura de Occidente desechó las cadenas milenarias que él mismo se había forjado. No por casualidad América surgió en el horizonte histórico como el país del porvenir y de la libertad" (E. O’Gorman, La invención de América. Investigación acerca de la estructura histórica del Nuevo Mundo y del sentido de su devenir, México DF: FCE, 2006, p. 180). Sin poder entrar ahora en los interesantes pormenores que llevan a O'Gorman a hablar de la "invención" de América, conste simplemente que hay caminos diferentes (aunque coherentes entre sí) que llevan a hablar del Nuevo Mundo como lugar del futuro. Asimismo, de la interpretación que se dé a esa concepción de América como tierra de futuro dependerá la concepción que adquiera la palabra "nuevo" en la expresión "Nuevo Mundo" (ibídem, pp. 192 ss.).

42 Cf. supra, nota 21. 
"Un pueblo no puede elegir entre varios estilos de vida: o vive conforme al suyo, o no vive. De un avestruz que no puede correr es inútil esperar que, en cambio, vuele como las águilas"43). En esta misma línea, la filosofía de Ortega contempla que cada circunstancia es un punto insustituible de entrada al universo y ofrece una perspectiva única de la realidad, que gana metafísicamente con cada nuevo punto de vista ${ }^{44}$. Confío en que esta larguísima cita, extraída de un texto tan señero del autor como es El tema de nuestro tiempo, resulte aclaradora:

[...] cada pueblo y cada época tienen su alma típica, es decir, una retícula con mallas de amplitud y perfil definidos que le prestan rigorosa afinidad con ciertas verdades e incorregible ineptitud para llegar a ciertas otras. Esto significa que todas las épocas y todos los pueblos han gozado su congrua porción de verdad, y no tiene sentido que pueblo ni época algunos pretendan oponerse a los demás, como si a ellos solos les hubiese cabido en el reparto la verdad entera. Todos tienen su puesto determinado en la serie histórica: ninguno puede aspirar a salirse de ella, porque esto equivaldría a convertirse en un ente abstracto con íntegra renuncia a la existencia.

Desde distintos puntos de vista, dos hombres miran el mismo paisaje. Sin embargo, no ven lo mismo. La distinta situación hace que el paisaje se organice ante ambos de distinta manera. Lo que para uno ocupa el primer término y acusa con vigor todos sus detalles, para el otro se halla en el último y queda oscuro y borroso. Además, como las cosas puestas unas detrás de otras se ocultan en todo o en parte, cada uno de ellos percibirá porciones del paisaje que al otro no llegan. ¿Tendría sentido que cada cual declarase falso el paisaje ajeno? Evidentemente, no; tan real es el uno como el otro. Pero tampoco tendría sentido que puestos de acuerdo, en vista de no coincidir sus paisajes, los juzgasen ilusorios. Esto supondría que hay un tercer paisaje auténtico, el cual no se halla sometido a las mismas condiciones que los otros dos. Ahora bien, ese paisaje arquetipo no existe ni puede existir. La realidad cósmica es tal, que sólo puede ser vista bajo una determinada perspectiva. La perspectiva es uno de los componentes de la realidad. Lejos de ser su deformación, es su organización. Una realidad que vista desde cualquier punto resultase siempre idéntica es un concepto absurdo ${ }^{45}$.

América, pues, tiene por delante una misión histórica: proporcionar un punto de vista nuevo sobre el universo y cumplir, con ello, su vocación.

43 J. Ortega y Gasset, España invertebrada, OC III, 498.

44 Ya en 1916, en el texto que abre el primer tomo de El Espectador, "Verdad y perspectiva", aseguraba el autor: "La verdad, lo real, el universo, la vida -como queráis llamarlo-, se quiebra en facetas innumerables, en vertientes sin cuento, cada una de las cuales da hacia un individuo. Si éste ha sabido ser fiel a su punto de vista, si ha resistido a la eterna seducción de cambiar su retina por otra imaginaria, lo que ve será un aspecto real del mundo. Y viceversa: cada hombre tiene una misión de verdad. Donde está mi pupila, no está otra: lo que de la realidad ve mi pupila no lo ve otra. Somos insustituibles, somos necesarios" (OC II, 163).

45 J. Ortega y Gasset, El tema de nuestro tiempo, OC III, p. 613. 
